\title{
International Journal of Genetics
}

International Journal of Genetics

ISSN: 0975-2862 \& E-ISSN: 0975-9158, Vol. 3, Issue 2, 2011, PP-66-71

Online available at: http://www.bioinfo.in/contents.php?id=25

\section{DETECTION OF DNA DAMAGE IN OBESE CARDIOVASCULAR DISEASE PATIENTS AND COMPARISON BETWEEN GENDERS: A CASE-CONTROL STUDY}

\author{
GANDHI G.*, KAUR J. AND MAHAJAN N. \\ Department of Human Genetics, GuruNanak DevUniversity, Amritsar 143 005, India \\ *Corresponding Author: Email-gandhig07@hotmail.com, jasmeetkaur009@yahoo.com, nareshmahajan1431@yahoo.co.uk
}

\begin{abstract}
-
Background- Obesity and cardiovascular disease (CVD) with the increased stress/ inflammation may cause DNA damage posing risk for malignancy hence assessment of DNA damage gains importance as a pre-cancerous biomarker.

Methods-The alkaline Single Cell Gel Electrophoresis assay was carried out in peripheral blood leukocytes of obese-CVD patients ( $n=28 ; 14$ males and 14 females) and matched controls ( $n=13 ; 7$ males and 6 females). Multiple regression and analysis of variance were performed for effect of confounding/specific factors on DNA damage and the Student's t-lest to compare differential values for factors associated with obesity-CVD and DNA damage.

Results-In patients, genomic damage was significantly higher ( $p<0.05)$ : damage frequency $(59.21 \%$ in males, $60.14 \%$ in females), mean DNA migration length $(37.53 \pm 4.74 \mu \mathrm{m}, 19.16 \pm 2.60 \mu \mathrm{m}$, respectively) in comparison to control data with significantly $(\mathrm{p}<0.01)$ increased damage in male patients. The attributes of obese-CVD patients and controls matched except for Body Mass Index (BMI), weight, waist circumference (WC) and waist hip ratio (WHR). Multivariate analysis of variance and multiple regression analysis revealed association of genetic damage with waist and hip circumferences in male patients. The t-test revealed that age, BMI, WHR, WC, cardiovascular disease sub-sets and drug usage had differential significance for genetic damage in female patients. Male patients with arrhythmia had significantly higher DNA damage as those on atenolol-rampril-furosemide therapy.

Conclusion- The significantly increased DNA damage in obese-CVD patients may be from the nature of CVD, treatment duration, drug combinations and adiposity and gains importance as it imples a higher risk for age -related diseases and cancer.
\end{abstract}

Received: October 14, 2011; Accepted: November 30, 2011

Key-words: SCGE/comet assay, Damage Frequency, Damage Index

Key Message- Obesity-CVD is a potent risk factor for DNA damage. The obese patients with CVD are therefore at risk for age -related diseases and carcinogenesis.

Running title- DNA damage in Obese Cardiovascular Disease patients

\section{Background}

Obesity is associated with an excess accumulation of adipose tissue and its occurrence has drastically increased in all population groups irrespective of age, sex, race, ethnicity, socioeconomic status, education level, or geographic region [1].Genetic, environmental, psychological and other factors have a part in manifestation of obesity. Of grave concern is the fact that obesity is an important determinant of cardiovascular diseases (CVD); it may be a leading cause of CVD or can co-exist with CVD risk factors like hypertension, hypercholesterolemia, diabetes, myocardial infarction, sleep-apnea, atherosclerosis, stroke and some cancers[2].Among other factors causing cardiovascular disease are elevated blood pressure, low density lipoprotein, cholesterol, low level of high density lipoprotein and elevated total blood cholesterol[3] which also have an association with obesity. Hence obesity is one of the major risk factors for atherosclerotic cardiovascular diseases.

The condition of obesity can trigger a stress response leading to release of free radicals. The risk of inflammation and the stress in adipocytes to check the accumulation of oxidative DNA damage in dividing and non-dividing cells can cause age- and sex- associated disease in obese individuals [4]. Oxidative stress may also be caused by inflammatory cytokines (TNF-a, interleukin 1-B and IL-6) as they can stimulate the production of reactive oxygen species (ROS) and reactive nitrogen species (RNS) by macrophages/monocytes [5]. Oxidative balance impairment has also been observed in overweight and obese persons [6].Increase in body mass index (BMI) and high waist circumference were reported to have an association with lipid hydroperoxide levels [7].

The detrimental effects of oxidative stress manifest in causation of damage to cellular macromolecules including the DNA which in turn can induce cancer and age- related diseases. Therefore, it is important to investigate DNA damage in persons with obesity and CVD, the conditions already known to have an association with oxidative stress $[8,9]$. The present study hence investigated for any DNA damage in peripheral blood leukocytes (PBL) of obese cardiovascular disease 
male and female patients. Evaluation of DNA damage in peripheral blood leuckocytes has been used as a biological marker in the detection, monitoringand prognosis of diseases and occupational health. Among various methods, the Single Cell Gel Electrophoresis (SCGE/ comet) assay is a rapid and simple technique with high intensity and sensitivity [10] and measures a mixture of direct strand breaks and DNA damage that is converted to strand breaks by alkaline treatment [11] with the level of DNA damage depending on the length of the comet tail.

\section{Subjects and Methods}

The study was cleared by the Institutional Ethics Committee of Guru Nanak Dev University and written; informed consent was taken from all volunteer participants. Patients seeking medical attention for cardiovascular diseases at the Health Centre, Guru Nanak Dev University, Amritsar and at Navpreet Hospital, Amritsar formed the study group. Healthy individuals of same age, sex and socio-economic status comprised the control group. Demographic and obesityand CVD-specific information of patients and of the control group was noted on a specially designed questionnaire. After recording blood pressure (mean value of three consecutive readings after a $10 \mathrm{~min}$ rest period), anthropometric measurements (height, weight, hip circumference, waist circumference for calculation of body mass index (BMI) and waist hip ratio (WHR) were taken using standard procedures[12]. As central obesity documents storage associations with cardiovascular disease risk and type-2 diabetes mellitus than overall adiposity, therefore measurements of waist circumference (WC) and hip circumference for waist hip ratio (WHR) were also recorded. Exclusion criteria for patients were those with inflammatory or immunological diseases and cancer. Medications included betablockers, calcium-channel blockers, and ACE inhibitors but no vitamin and/or antioxidant therapies. The control group had no past or present history for diabetes, hypertension, heart disease or cancer and they were not on nutritional supplements. Patients with [13] BMI $\geq 25.0$ $\mathrm{kg} / \mathrm{m}^{2}$ and healthy individuals with BMI $\leq 22.9 \mathrm{~kg} / \mathrm{m}^{2}$ formed the study group. Finger-prick blood samples $(\sim 300 \mu \mathrm{l})$ were collected for evaluation of DNA damage in micro-centrifuge tubes containing EDTA (ethylene diamine tetra acetic acid).

Cell viability was assessed by the Trypan-Blue (1\%) dyeexclusion method and was $>90 \%$ for all samples and hence these were processed for the alkaline SCGE [14] modified method [15] to assess DNA damage using locally-available chemicals. For this, individual cells were embedded in a thin agarose gel layered on glass slides; cellular proteins were lysed and DNA was allowed to unwind under alkaline conditions followed by electrophoresis. This later allows DNA fragments to migrate away from the nucleus towards the anode which can be visualized after staining. In brief, whole blood samples $(30 \mu \mathrm{l})$ were mixed in $0.5 \%(\mathrm{w} / \mathrm{v})$ low melting agarose and sandwiched between a layer of $1.0 \%(\mathrm{w} / \mathrm{v})$ normal melting agarose and a top layer of $0.5 \%(\mathrm{w} / \mathrm{v}$ ) low melting agarose on clean microscope slides. The slides were then immersed in chilled working lysing solution $(\mathrm{NaCl}(2.5 \mathrm{M})$, Trisaminomethane $(10 \mathrm{mM}), 12 \mathrm{gNaOH}$ pellets, EDTA $(100 \mathrm{mM}) \mathrm{pH}=10$, supplemented with DMSO (10\% v/v) and Triton X-100 (1\% v/v) and kept at $4^{\circ} \mathrm{C}$ for a minimum of 2 hours followed by an alkaline treatment time of 25 minutes for DNA unwinding in electrophoresis buffer $(300 \mathrm{mM} \mathrm{NaOH}, 1 \mathrm{mM}$ EDTA, $\mathrm{pH}>13$ ) and then electrophoresed $\mathrm{n}$ the same buffer for $20-25 \mathrm{~min}$ at $25 \mathrm{~V}(0.8 \mathrm{~V} / \mathrm{cm})$ and $300 \mathrm{~mA}$. The slides were neutralised $(0.4 \mathrm{M}$ Tris- $\mathrm{HCl}, \mathrm{pH}=7.5)$ for $10 \mathrm{~min}$ and then fixed and allowed to air-dry overnight. Staining was carried out with $20 \%$ silver nitrate [16] and then slides were dried and stored till analysis. For each sample, 100 cells (50/slide) were visually scored for DNA damage. A calibrated ocular micrometer was used for the measurement of DNA migration length. Deduction of cell radius from the total length of the comet gave the extent of DNA migration. Visual categorization (0-IV) of cells with tails was also done[17].

Statistical analysis was performed using SPSS (version 16.0). The distributions of mean DNA migration length did not show a departure from normality and therefore parametric tests were performed. The Student's t-lestfor dependent variables was used to compare means of average DNA migration length and per cent cells with tails for values obtained for patients and controls for factors associated with the obesity, CVD and DNA damage viz. age, BMI, WHR, medication and CVD subtypes. The $2 \times 2$ contingency Chi-square test was performed on the attributes of the obese cardiovascular individuals and control groups. Multiple regression analysis and analysis of variance (ANOVA) were carried out to find any effect of confounding and specific factors (independent variables like age, height, weight, BMI, WHR, alcohol consumption, mobile phone use) in causing the observed genetic damage (dependent variable). Significance was taken at $p<0.05$ and $p<0.01$ as appropriate.

\section{Results}

The demographic information on patients $(n=28 ; 14$ of each sex) diagnosed by the physicians with CVD (hypercholesterolemia, history of heart attack, atherosclerosis, sleep apnea, angina) is presented in Tables 1and 2. Age- and sex- matched healthy individuals ( $n=13 ; 6$ females, 7 males) formed the control group. Treatment included combinational drugs (betablockers, diuretics, ACE inhibitors and calcium-channel blockers).

\section{Demographic information}

Patient and control groups were in the age range of 40$71 \mathrm{yr}$ (patients-mean age 53.28y for males, 62.71y for females; controls 53.00y for males and 57.50y for females), with mean BMI of $31.35 \mathrm{~kg} / \mathrm{m}^{2}$ for male- and $32.39 \mathrm{~kg} / \mathrm{m}^{2}$ for female- patients and $21.92 \mathrm{~kg} / \mathrm{m}^{2}$ for male- and $21.07 \mathrm{~kg} / \mathrm{m}^{2}$ for female- controls. The $2 \times 2$ contingency Chi-square test on the attributes of the 
patients and controls revealed group-matching except for weight, waist circumference, BMI and WHR (Table 1).

\section{Multiple regression analysis}

The objective of regression analysis is to determine the relation between two variables in which one is dependent and the other is independent and to study the shape of the curve of relationship and to find the reason for relationship. In the present study, multiple regression analysis was performed (Table 3) to assess the relationship between variables which could be confounding factors (i.e. age, weight, height, mobile use, BMI, WHR and dietary pattern), and dependent variables (DF and DNA migration length) in both patient and control groups. On the basis of correlation coefficient ' $r$ ' and probability ' $p$ ', hip and waist circumferences $(p<$ 0.05 ) among these showed contribution to DNA damage in male patients and in obese cardiovascular females, only mobile phone usage contributed to DNA damage. In controls, contributions were as for ANOVA results.

\section{Analysis of variance (ANOVA)}

ANOVA was performed (Table 4) to see the significance of regression lines. Significance $(p<0.05)$ in male patients for DNA damage was also observed with hip and waist circumferences; in female patients, significance was observed for mobile phone users. In control females, significance with hip and waist circumferences and BMI and in control males, with mobile phone usage was observed

\section{DNA damage}

The results obtained from the SCGE assay for Damage Frequency (DF-percent cells with tails), Damage Index (DI-arbitrary score) and the mean DNA migration length (extent of DNA damage) are presented (Table 5). All these are DNA damage parameters where DF indicates cells with tails, DI, arbitrary score (DNA strand breaks)[17] and DNA migration is extent of DNA damage. In combined male and female patients, the percent cells with tails (DF) were $59.68 \pm 6.30$ being significantly higher $(p<0.05)$ than in the total control group (28.34 \pm 3.19 ). The extent of DNA damage (mean DNA migration length- $28.34 \pm 3.19 \mu \mathrm{m}$ ) was also higher in patients but not statistically from value in controls $(20.78 \pm 3.11 \mu \mathrm{m})$. Damage index in patients $(64.03 \pm 7.28)$ was also significantly higher $(p<0.05)$ compared to control value $(36.23 \pm 7.84)$. The patients and controls matched except for BMI, and weight $(p<0.5)$. Regression analysis revealed that in patients, hip and waist circumferences while in controls, mobile phone usage was significant for percent cells with tails.

The mean DNA migration length in male patients $(37.52 \pm 4.74 \mu \mathrm{m})$ was significantly higher $(p=0.002$; $\mathrm{p}<0.01)$ than in females $(19.61 \pm 2.60 \mu \mathrm{m})$. Significant difference also occurred on comparing male patients to male controls for DI based on visual scoring which also revealed that cells in categories 0 -III were present in some male patients; female patients only had cell damage of categories 0 - II while in controls mostly category 0 and some in I were present.
DNA damage in relation to age, BMI, WHR, comorbidities, CVD subsets, drug combinations

The Student's' t-test was performed separately for male and female patients with their respective controls on the results obtained from the SCGE assay for Damage Frequency (DF-percent cells with tails) and the mean DNA migration length (extent of DNA damage) to analyze whether age, BMI, WHR, co-morbid conditions, CVD sub-sets and drug combinations exhibited genetic damage among different groups.

Female patients- Significant increase in the older aged group in mean DNA migration length $(50-60 \mathrm{y}, 14.90 \pm$ $0.21 \mu \mathrm{m}$ and in 61-71y, $21.53 \pm 0.47 \mu \mathrm{m} ; \mathrm{p}<0.001$ ) was observed. In BMl, the two ranges $25.0-29.9 \mathrm{~kg} / \mathrm{m}^{2}$ and $\geq 30.00 \mathrm{~kg} / \mathrm{m}^{2}$ showed significant differences for both percentage of cells with tails and mean DNA migration length ( $\mathrm{t}_{\text {cal }}=2.654, \mathrm{t}_{\mathrm{tab}}=1.782, \mathrm{df}=12, \mathrm{p}<0.05$; $\mathrm{t}_{\mathrm{cal}}=$ 14.11, $\left.\mathrm{t}_{\text {tab }}=3.055, \mathrm{df}=12, \mathrm{p}<0.001\right)$, respectively. WHR in patients was higher $(>0.85)$ than in controls $(<$ 0.85 ) and there was significant increase in patients for both, percentage of cells with tails and mean DNA migration length. Highly significant differences were observed in patients with diabetes and hypertension from control values for both, percentage of cells with tails and mean DNA migration length $\left(\mathrm{t}_{\mathrm{cal}}=6.328, \mathrm{t}_{\mathrm{ab}}=3.169, \mathrm{df}=\right.$ $10, p<0.001 ; t_{\text {cal }}=39.828, t_{\text {tab }}=3.169, d f=10, p<$ 0.001 ). In case of cardiovascular disease sub-sets, highly significance was revealed in the subsets of hypercholesterolemia and atherosclerosis ( $\mathrm{t}_{\text {cal }}=25.453$, $\left.t_{\text {tab }}=5.841, \mathrm{df}=3 ; p<0.001\right)$ for mean DNA migration length and for percentage of cells with tails ( $t_{c a l}=4.545$, $\left.t_{\text {tab }}=4.541, \mathrm{df}=3 ; \mathrm{p}<0.001\right)$. For drug usage, the combinations captoril-cyclopenthiozide and atenololramipril-furosemide showed comparative damage and the combination, bisopril- furosemide showed maximum damage.

Male patients-Though 40-53y patient group on comparison with the same age range controls showed significant result for percent cells with tails (tcal $=2.24$, tab $=2.228, d f=13, p<.0 .05$ ), yet DNA migration lengths were non-significant between patient groups. In BMI, the two ranges $\geq 25.0-29.9 \mathrm{~kg} / \mathrm{m}^{2}$ and $\geq 30.00 \mathrm{~kg} / \mathrm{m}^{2}$ showed no significant differences though there was more genetic damage in the higher BMI category. As per male cut-offs for WHR, in patients there were nine with $<1.0$ and only five were obese $(\geq 1.0)$ but the DNA damage was not significant in these categories. Among the three sub- sets of co-morbidities, patients with CVD, obesity, hypertension and diabetes had maximum genetic damage. With respect to the five subsets of CVD as diagnosed by the physician i.e. arrhythmia, angina, hypercholesterolemia, sleep apnea and heart attack occurrence, the patients with arrhythmia had statistical significance ( $\left.\mathrm{t}_{\text {cal }}=2.362, \mathrm{t}_{\mathrm{tab}}=2.160, \mathrm{df}=13, \mathrm{p}<0.05\right)$ for mean DNA migration length compared to control value. Patients on atenolol-rampril-furosemide had most damage followed by those on atenolol-rampril combination. 


\section{Discussion}

The SCGE assay is one of the most sensitive and accurate methods for assessing DNA damage and DNA damage in lymphocytes has been used as a biological biomarker in the detection, monitoring and prognosis of chronic degenerative diseases such as atherosclerosis[18]. In the present study, significant DNA damage in peripheral blood leukocytes of obese CVD patients has been observed. In literature, various studies have documented genetic damage in CVD and in the atherosclerotic plaques and in heart muscles. Increased BMI and adiposity have also been observed to be associated with DNA damage. The presence of increased free radicals and decreased antioxidants manifesting as oxidant stress has also been reported in a number of studies in CVD patients and with the condition of obesity.

Oxidative stress has been reported to induce the pathogenesis of various vascular diseases. Patients suffering from cardiovascular disease are vulnerable to oxidative stress because of imbalance or impaired status of antioxidants and free radicals [19] and oxidative stress plays an important role in DNA damage, as it generates free radicals which cause degradation of proteins, DNA etc. Free radicals react to form pyroxynitrite which is a potent cytotoxic oxidant that can cause peroxidation of lipids, degradation of DNA and oligonucleosomal fragmentation [20]. Tissue injury, protein oxidation and DNA damage can also be caused by increased nitric oxide due to ROS [21]. In the present study, significant increase in DF-percent cells with tails $(p<0.05)$ was observed in patients with various co-morbid conditions (obesity, CVD, hypertension; obesity, CVD, diabetes. In fact, obesity is associated with an increased risk of hypercholesterolemia, diabetes and hypertension, which are all well correlated to cardiovascular disease [22]. The oxidative stress in accumulated fat also mediates the obesity-associated development of metabolic syndrome by dysregulated production of adipocytokines and the increased ROS leads to elevation of systemic oxidative stress. Offensive (PAI-1, TNF-a, IL-6, MCP-1, angiotensinogen) and defensive (adiponectin, leptin) adipocytokines lead to the pathogenesis of the metabolic syndrome [23].

A number of studies have revealed the association of DNA damage with obesity and in heart disorders. DNA damage in patients with obesity was significantly higher than without obesity implying that obesity is an independent risk factor of DNA damage [24]. Increased levels of DNA damage was also reported in CAD patients $[25,26]$. In fact, DNA damage significantly contributed to atherosclerosis [27] probably from oxidative stress [28, 29]. Other studies have also documented that DNA damage has significance in the mechanism of atherosclerosis[30,31]. Higher DNA damage (urinary 8hydroxydeoxyguanosine concentration-8-OHdG) in type2-diabetes as well as self-reported CVD in 959 participants of the Boston Puerto Rican Health Study[32] has been documented. Chromosomal and DNA damage were observed in circulating cells of patients with atherosclerosis and the atherosclerotic plaque also had manifestations of deletions/duplications, microsatellite instability as well as oxidative DNA damage and DNA breaks[33,34]. A significantly higher frequency of micronuclei was observed in CAD patients compared with controls [35]. Recently, significantly higher levels of MDA, nitrite/nitrate and DNA damage in the patients was observed compared to the control [36].

With increase in age there is also an increase in DNA damage as antioxidant enzymes and DNA damage repair capacity decreases $[34,37]$. DNA damage was elevated in the older obese CVD patients of the present study also. The risk of inflammation and the stress in adipocytes to check the accumulation of oxidative DNA damage in dividing and non-dividing cells can cause ageand sex- associated disease in obese individuals [4]. In male patients of the present study, a significant increase in extent of DNA damage has also been observed.In an earlier study in literature [38], males had higher ( $p<$ 0.001) levels of single-strand breaks and alkali-labile sites than in females though no difference was seen for oxidative lesions. Higher DNA damage in nasal cells and leukocytes was found in male medical students compared to female students and control subjects[39].Micronucleated cell frequency was significantly higher in male coronary artery disease patients $(80.4 \%)$ than in women (19.6\%) as compared to control samples were also micronucleus frequency value was raised in men $(72 \%)$ than women $(28 \%$ t value 0.698)[40]. Estrogen levels are known to influence gender differences of urinary 8-OHdG levels [41] and differences in other hormonal levels among genders may be similarly acting directly or indirectly in patients in the present study. The different individual backgrounds, additional confounding factors and the individual's ability to repair DNA [42] also cannot be disregarded. The present group also included some male patients with alcohol drinking habit. Chronic treatment of alcohol induced aneuploidy in vitro [43] and single strand breaks [44]. The presence of other co-morbidities and factors like BMI, age, stress, medication play can also cause DNA damage. DNA damage was found to be higher in patients with cardiometabolic syndrome probably from free radicals generated from various lifestyles including alcohol consumption; an increase in free radicals with age was also observed [45].

Other triggers for DNA damage besides obesity and/or CVD combined with diabetes/hypertension may include the combinational drug therapy. Calcium-channel blockers with nitrite examined for liver DNA fragmentation, as detected by the comet assay, in rats revealed a significant increase of both tail length and tail moment, indicative of an increased frequency of DNA single-strand breaks and alkali-labile sites;[46]chromosomal damage in ethosuximide (a calcium-channel blocker)-treated human lymphocytes was also documented[47]. On the other hand, ACE inhibitor suppressed chemically-induced colon carcinogenesis by attenuating chronic inflammation and 
reducing oxidative stress in obese mice [48]. Angiotensin II receptor blockers by modulating inflammatory responses [cf49] suppressed arteriosclerotic lesions in animal models and in patients with coronary artery disease or hypertension. Recently, furosemide was reported as genotoxic in bone marrow cells and hepatocytes of mice[50].

The reports from literature document that oxidative stress plays an important role in obesity and CVD and that DNA damage is also prevalent in obese and/or CVD patients. This DNA damage probably gets generated from action of free radicals which can lead to degradation of lipids, proteins, DNA, etc. The present study also indicates that obesity with cardiovascular disease causes significant DNA damage as compared to controls which may be happening in a similar fashion. Diabetes and hypertension were prevalent co-morbid conditions in males as was alcohol drinking besides increased adiposity (BMI, WHR) which could be factors in the causation of increased DNA damage. Encouragement of physical exercise and weight control management if followed early in life may decrease the chances of developing obesity and cardiovascular disorders. Intervention strategies to prevent/ mitigate DNA damage include antioxidant/ micronutrient intake and moderate exercise regimen. The results from this study reveal that obese persons with CVD (especially males) have DNA damage and this has other serious health implications as DNA injury can induce mutations that cause cancer or cell death or senescence, and contributing to aging and diseases related to ageing [51].

\section{Limitations}

Though this seems to be a first study from this region, there are some limitations. The patients had different CVD conditions and they were on combinational drug therapy because of other co-morbidities. Subjects with newly diagnosed CVD before initiating therapy would be more beneficial for assessing the predictive value of the comet assay since the assay outcome would not be affected by disease status or treatment. To further characterize this outcome as a potential biomarker of cancer development, the study should be replicated with pre-treated samples and a larger sample size. However in this study, after adjustment for confounding factors, the difference between cases and controls remained significant and this measure of DNA damage may prove to be helpful early marker of risk for cancer and agerelated changes. Anotherlimitation has been the in availability of enough blood samples and so oxidative stress parameters could not be studied. Future investigations must include this. The investigation for oxidative stress indices however cannot detract the observed DNA damage differences between patients and controls.

In summary, our findings reveal elevated levels of damaged DNA associated with obesity, CVD and/or the therapy in the absence of other exposures. A larger prospective study as this could contribute to the identification of individuals with increased cancer susceptibility and may prove useful for follow-up for obese patients newly diagnosed with CVD.

\section{Conclusion}

The results of the present study imply that obesity-CVD is a potent risk factor for DNA damage probably induced by oxidative stress. The obese patients with CVD are therefore at risk for age -related diseases and carcinogenesis.

\section{Conflicts of interest}

The authors have no conflicts of interests.

\section{Authors' contributions}

GG contributed to the concept, design and preparation of manuscript, and $\mathrm{JK}$ and $\mathrm{NM}$ equally towards experimental work, literature collection and statistical analysis.

\section{Acknowledgements}

The work was carried out from departmental grants (UGC-SAP).

\section{References}

[1] National Center for Chronic Disease Prevention and Health Promotion Obesity (2011) Halting the Epidemic by Making Health Easier At A Glance [http://www.cdc.gov/chronicdisease/resources /publications/AAG/obesity.htm]

[2] World Health Organization (2011) Obesity and overweight Fact sheet $N^{\circ} 311$. [http://www.who.int/mediacentre/factsheets/fs3 11/en/index.html]

[3] Hingdon JV, Fri B (2003) Atheroscler Thromb Vasc Biol, 23: 365-367.

[4] Moller P., Knudsen L.E., Loft S., Wallin $H$. (2000) Am Ass Cancer Res, 9: 1005-1015.

[5] Ziccardi P., Nappo F., Giugliano G., Esposito K.,Marfella R., Cioffi M., D'Andrea F. , Molinari A.M.,Giugliano D. (2002) Circulation,105: 804809.

[6] Cazzola R., Rondanelli M., Trotti R., Camerotto C., CestaroB. (2008) Mediterranean Journal of Nutrition And Metabolism, 1: 19-24, Doi: 10.1007/S12349-008-0003-6

[7] Brown L.A., Kerr, Whiting P., Finer N., McEneny J., Ashton T. (2008) Obesity 2009, 17: 460-466. Doi: 10.1038/oby. 590.

[8] Vijayalakshmi B., Chandrasekhar M. (2009) The Indian Journal of Animal Sciences, 79: 258-268.

[9] Di Renzo L., Galvano F., Orlandi C., Bianchi A., Di Giacomo C. , La Fauci L., Acquaviva R., De Lorenzo A. (2010) Obesity 2010, 18: 21252130, doi:10.1038/oby. 50

[10] Dhawan A.,Mathur N.,Seth P.K. (2001) Mutat Res, 474: 121-128. 
[11] Tice R.R., Agurell E., Anderson D., Burlinson B., Hartmann A., Kobayashi H., Miyamae Y., Rajas E., Rayu J.C., SasakiY.F. (2000) Environ Mol Mutagen, 35 : 206-221.

[12] Weiner J. S., Lourie J.A. (1981) Human Biology: New York: Academic Press 439 p.

[13] WHO expert consultation (2004) The Lancet, 363: 157-163.

[14] Singh N.P., McCoy M.T., Tice R.R., Schneider E.L. (1998) Exp Cell Res, 175: 184-191.

[15] Ahuja Y.R., Saran R. (1999) Cytol Genet. 34: 57-62.

[16] Delincee H. (1995) Comet Newslett, \#3.

[17] Collins A. R. (2004) MolBiotechnol, 26: 249261.

[18] Mendoza-Nunz V.M., Sanchez-Rodrigue M. A., Retana-Ungalda R., Vargas-Guadarrama L.A., Altamirana-Lazano M.A. (2001) Mech Aging Dev, 122 : 835-847.

[19] Kashyap M., Yadav V., Sherawat B., Jain S., Kumari S., Khullar M., Sharma P., Nath R. (2005) Mol Cell Biochem, 277: 89-99.

[20] Hemnani T., Parihar M.S. (1998) Ind J PhysiolPharmacol, 42: 440-452.

[21] Xu S., Touyz R.M. (2006) Can Cardiol, 22: 947-951.

[22] Beltowski J., Wojcicka G., Gorny D., Marciniak A. (2000) J PhysiolPharmacol, 51: 883-896.

[23] Furukawa S., Fujita T., Shimabukuro M., Iwaki M., Yamada Y., Nakajima Y., Nakayama O., Makishima M., Mastuda M., Shimomura I. (2004) J Clin Invest, 114 :1752-1761.

[24] Demirbag A., Hosoda H., Ito K., Iwana S., Miura N., Matsuoka H., Kondo C., Kojima M., Kangawa K., Sugihara S.(2005) Diabetes,51: 3408-3411.

[25] Young I. S., Woodside J. V. (2001) J Clin Pathol, 54:176-186.

[26] Botto N., Rizza A., Colomba M.G., Mazzone A.M., Masetti S., Clerico A., Biagini A., Andreass M.G.(2001)Mutat Res, 493 : 23-30.

[27] AndreassiM. G.,Botto N. (2003) Trends in Cardiovascular Medicine, 13: 270-275.

[28] Botto N., Masetti S., Petrozzi L., Vassalle C., Manfredi S., Biagini A., Andreass M.G. (2002) Coronary Artery Disease, 13: 269-274.

[29] Andreassi M. G. (2003) Mutat Res, 543: 6786.

[30] Mahmoudi M., Mercer J., Bennett M. (2006) Cardiovascular Res; 71:259-68.

[31] De Flora S., Izzotti A. (2007) Mutat Res, 621: 5-17.

[32] Lai C.Q., Katherine L., Tucker I.D., Parnell X.A., Adiconis B. G.B., Griffith J., Meydani M., Ordova' S J.M. (2008) The Boston Puerto Rican Health Study Diabetes, 57:809-816.

[33] Martinet W., Knaapen M.W.M., De Meyer G.R.Y., Herman A.G., Kockx M.M. (2002) Circulation, 106:927-932.
[34] Andreassi MG (2008) Journal of Molecular Medicine, 86: 1033-1043.

[35] Guven M., Guven G.S., Oz E., Ozaydin A., Batar B., Ulutin T., Hacihanefioglu S., Domanic N. (2007) Heart Vessels, 22:355-360.

[36] Rajesh K. G., Surekha R. H., Mrudula S. K., Prasad Y., Sanjib K. S., Prathiba N. (2011) Singapore Med J, 52: 283-288.

[37] Goukassian D., Gad F., Yaar M., Eller M.S., Nehal U.S., Gilchrest B.A. (2000) FASEBJ, 14: 1325-1334.

[38] Hofer T., Hanna L. K., Moller L. (2006) Free RadicRes, 40:707-714.

[39] Fortoul T.I., Valverde M. , López M.C ., AvilaCosta M.R., Avila-Casado M.C., MussaliGalante P., Gonzalez-Villalva A. , Rojas E. , Ostrosky-Shejet P. (2004) Environmental Research, 94: 243-248.

[40] Ramakrishnan V., Gowtham Kumar S., Thiyagarajan G., Madhusudhanan N., Vincent S. (2011) Int J Med Res, 1: 111-117.

[41] Wong R.H., Yeh C.Y., Hsueh Y.M., Wang J.D., Lei Y.C., Cheng T.J. (2003) Mutat Res, 535:181-186.

[42] Kohno T., Shinmura K., Tosaka M., Tani M., Kim S.R., Sugimura H., Nohmi T., Kasai H., Yokota J. (1998) Oncogene, 16:3219-3225.

[43] Benassi-Evans B., FenechM. (2011) Mutagenesis, 26:421-429.

[44] Rulten S. L., Hodder E., Ripley T .L., Stephens D. N.,Mayne L. V. (2008) Clinical and Experimental Research, 32: 1186-1196. doi: 10.1111/j.1530-0277.2008.00673.x

[45] Simon A.S., Roy D. D., Jayapal V., Vijayakumar T., (2010) Indian Journal of Clinical Biochemistry, 25:164-168.

[46] Martelli A., Robbiano L., Grossi S., Mattioli .F, Brambilla G. (2007) Toxicology, 238: 211-215.

[47] Ghiraldini F.G., Mello M.L.S. (2010) Cell Biollnt Rep, 17(1).

[48] Kubota M., Shimizu M., Sakai H., Yasuda Y., Ohno T., Kochi T., Tsurumi H., Tanaka T., Moriwaki H. (2011) Biochemical and Biophysical Research Communications, 410: 108-113.

[49] Yoshinori S. (2006) Clinical Science, 110: 379386.

[50] Mondal S. C., Tripathi D. N., Vikram A., Ramarao P., JenaG. B. (2011) Fundamental \& Clinical Pharmacology, 25: doi: 10.1111/j.14728206.2011.00927.x

[51] Hoeijmaker J.H.S. (2009) N Engl J Med, 361:1475-1485. 